\title{
An Accurate Self-Commissioning Technique for Matrix Converters Applied to Sensorless Control of Synchronous Reluctance Motor Drives
}

\author{
Fausto Stella, Arzhang Yousefi-Talouki, Shafiq Odhano, Member, IEEE, \\ Gianmario Pellegrino, Senior Member, IEEE, and Pericle Zanchetta, Senior Member, IEEE,
}

\begin{abstract}
The compensation of converters' nonlinear voltage error is crucial in encoder-less control of ac motor drives. In this paper, a new self-commissioning and compensation method is proposed for matrix converters (MC). Similar to what done in the past for voltage source inverters, the MC voltage error is identified before the drive start and stored in a look-up table (LUT), later used for error compensation and accurate voltage estimate. Different from what observed in the past, the effect of parasitic capacitors on nonlinear voltage error of MCs in four-step current based commutation is observed and studied. Eventually, this method is applied to the sensorless control of a synchronous reluctance (SyR) motor drive, using the direct flux vector control (DFVC) concept. Experimental results are presented to validate the effectiveness of proposed self-commissioning in improving the performance of sensorless control at standstill and low speed.
\end{abstract}

Index Terms-Active flux; Matrix converter; selfcommissioning; sensorless; synchronous reluctance.

\section{INTRODUCTION}

$\mathbf{R}$ OTOR position information is one of the most important parameters in synchronous motor drives. Usally, mechanical sensors such as resolvers and encoders, mounted on rotor shaft, are used to acquire rotor position information. However, using these sensors not only increases the total drive cost, but also decreases the reliability of the system at the same time. Hence, sensorless control techniques are attractive alternatives that have been proliferated in the last few decades and drawn widespread research attentions in both academia and industry [1]-[4]. In general, rotor position estimation techniques can be divided into two main categories: high frequency (HF) signal injection [1], [2] and model based [3], [4] methods. The former, which is based on magnetic saliency tracking, is suitable for standstill and low speed levels, while for higher speeds, the latter one is adopted.

In adjustable speed drives, stator voltage is needed for state variable observers. However, since pulse width modulation (PWM) voltage measurement is challenging and extra hardware is required, reference voltage is used instead. But, due to

F. Stella, A. Yousefi-Talouki, and G. Pellegrino are with the Department of Energy, Politecnico di Torino, 10129 Turin, Italy (email: fausto.stella@polito.it; arzhang.yousefitalouki@polito.it; gianmario.pellegrino@polito.it).

S. Odhano and P. Zanchetta are with the Department of Electrical and Electronics Engineering, University of Nottingham, Nottingham, UK NG7 2RD (email: shafiq.odhano@nottingham.ac.uk; pericle.zanchetta@nottingham.ac.uk).

Manuscript received February 22, 2018; revised May 5, 2018; accepted June 16, 2018. converters' nonlinearities, there is an error between the actual motor terminal voltage (PWM voltage) and reference voltage, which gives rise to inaccurate state variable observations. Converter nonlinearities are due to different reasons such as dead time, voltage drops on insulated gate bipolar transistors (IGBT), and parasitic components [5]-[7]. Diverse discussions have been addressed in the literature that one of the sources of errors in rotor/flux position estimation is converter nonlinearities that can affect the efficacy of the sensorless control techniques, especially at low speeds [8]-[12].Therefore, these errors should be identified and compensated accurately. It was extensively discussed in [8] that how inverter nonlinearities cause the distortion of injected HF pulsating voltage and eventually influence the estimation of rotor/flux position. Literature [9] investigated the effect of inverter nonlinearities on rotating HF voltage and proposed a method to compensate these errors. A compensation technique was proposed in [10] to overcome inverter nonlinearities effect in sensorless control drives by aid of trapezoidal voltage. A self-commissioning technique was proposed in [11], [12] to identify inverter nonlinear voltages before drive start-up, with no need of IGBT datasheet and extra hardware. The effect of compensation of voltage error in sensorless control of induction motor was studied in these papers.

A three-phase to three-phase matrix converter as a single stage power converter, is superior to conventional voltage source inverters (VSIs) due to different merits such as lack of bulky dc-link capacitors, adjustable input power factor, bidirectional power flow, and high quality output power waveforms [13]. Due to the absence of electrolytic capacitors, these converters are employed in applications in which low volume and high reliability are demanded. In recent years, matrix converter is coming to be known as a matured technology and its applications are extended from adjustable ac drives to aerospace sectors [14], [15]. Analogous to VSIs, due to the commutation delay, ON-state voltage drop, and parasitic effects, the output voltage of matrix converter becomes distorted, which causes inaccurate state observations when voltage is needed as an input. Hence, the nonlinear voltage errors must be properly compensated. Several papers have focused on identification and compensation of MCs nonlinear voltage errors [16]-[23] and demonstrated that there are two sources of error in MCs: edge uncertainty (EU) effect which is due to commutation delay, and $\mathrm{ON}$-state voltage drop on switching devices. Articles [16] and [17] have investigated 
the nonlinear voltage error of MCs coming from four-step current based commutation and voltage drop on IGBTs. It was shown that in MCs, the error caused by commutation delay (EU effect) and ON-state voltage drop error tend to cancel out each other. The identified voltage errors then have been used for compensation techniques in sensorless control schemes [18]-[20]. A compensation technique was proposed for voltage based commutation of MCs considering the parasitic capacitance effect in [23]. However, to compensate the effect of parasitic capacitors along with commutation and $\mathrm{ON}$-state voltage errors, accurate knowledge of power devise is required. A self-commissioning technique was proposed in [21] capable of identifying $\mathrm{MC}$ voltage error before drive startup and not requiring IGBT datasheet. Then, a compensation technique was proposed in stationary $\alpha \beta$ frame to omit nonlinear voltage errors. The same technique was applied for sensorless control of MC-fed synchronous reluctance motor drives in [22].

In all aforementioned methods for four-step current based commutation, the effect of parasitic capacitors was neglected in commutation process. In other words, the turn-on and turnoff time of switches was supposed to be constant, while these times are affected by parasitic capacitors in reality. In this paper, a four-step current based commutation and double-sided switching pattern is adopted [13]. First, the nonlinear voltage errors of MCs is modeled and the effect of parasitic capacitors on commutation voltage error is studied. It will be shown that the total voltage errors in four-step current based commutated MCs is higher at lower currents because of parasitic capacitors. Then a self-commissioning technique is proposed to identify nonlinear voltage errors. The identified voltage errors are stored in a look-up table extending from low current values to high current values. The advantage of proposed self-commissioning technique is that neither extra hardware is required nor device datasheet. Then, a compensation technique in stationary reference frame $(\alpha \beta)$ is used to compensate the effect of nonlinear voltage errors. Eventually, the proposed technique is applied on a sensorless control method for pure synchronous reluctance motor drives. Without losing generality of proposed method, the control scheme is direct flux vector control which works on stator flux frame at constant switching frequency. The sensorless control technique works at standstill and high speed with combination of HF signal injection and active flux (AF) methods [2]. The effectiveness of the proposed self-commissioning technique applied on sensorless control is demonstrated on a $2.2 \mathrm{~kW}$ SyRM test bench. In summary, the contributions of this paper are listed as follows.

- The effect of parasitic capacitors on voltage error in fourstep current based commutation is studied and modeled.

- a self-commissioning technique is proposed to identify the total voltage error of $\mathrm{MC}$ and results are stored in a LUT covering a wide range of current from low current to high current values.

- proposed technique is applied to a sensorless control technique for MC-fed SyRM drive and the effect of compensation of nonlinear voltage errors on rotor position estimation is studied experimentally.
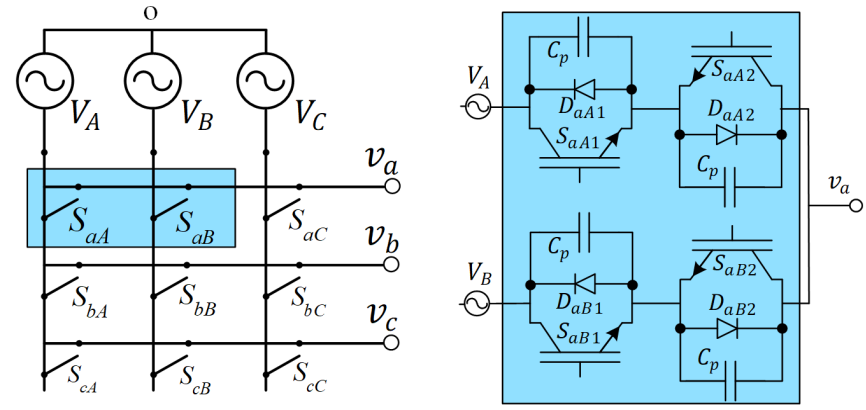

Fig. 1. MC topology.

\section{Matrix Converter Nonlinear Voltage Errors}

The schematic diagram of a three-phase to three-phase matrix converter is illustrated in Fig.1, where each bidirectional switch can connect one of the input phases to one of the output phases. Indirect space vector modulation (ISVM) is adopted in this paper [21]. The aim of ISVM is to synthesize the output voltage vectors and the phase angle of input current vectors at the same time. Fig. 2 reports the output voltage and input current vectors and their corresponding sectors. In the following analysis both output and input sectors are assumed to be (1). In Fig.2 (a), $v_{o}^{*}$ and $\theta_{o}^{*}$ are the amplitude and phase angle of reference output voltage vector, respectively. Also in Fig.2 (b), $V_{\text {in }}$ denotes for input voltage vector, and $I_{\text {in }}$ stands for input current vector drawn from ac sources (before input filters). $I_{m c}$ is the input current vector of $\mathrm{MC}$, after input filters. $\theta_{i n}^{*}$ is the phase angle of $V_{i n}$, and $\Delta \theta$ is the displacement angle between $V_{i n}$ and $I_{m c}$, due to presence of input filters. In ISVM technique, the phase angle of $I_{m c}$, i.e., $\theta_{i n}^{*}-\Delta \theta$ is controlled in order to obtain a unity input power factor in ac main side.

Generally, there are two kinds of nonlinear voltage errors in MCs: Edge uncertainty error due to commutation delay, and $\mathrm{ON}$-state voltage drop, that will be discussed in the following.

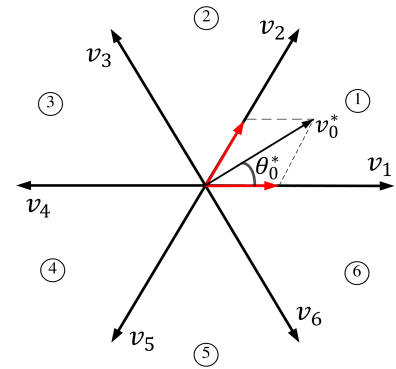

(a)

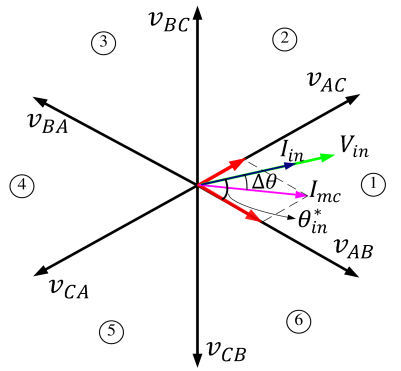

(b)
Fig. 2. MC space vectors: (a) output voltage vectors, (b) input current vectors.

\section{A. Edge uncertainty voltage error}

By changing the output phase voltage from one input phase to another one, a voltage error is introduced due to commutation delay which is dependent on switching pattern and commutation sequence. A double-sided switching pattern and 


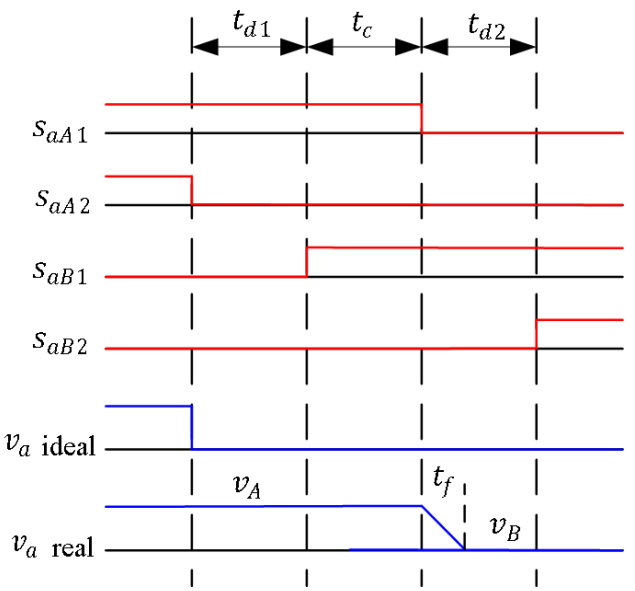

(a)

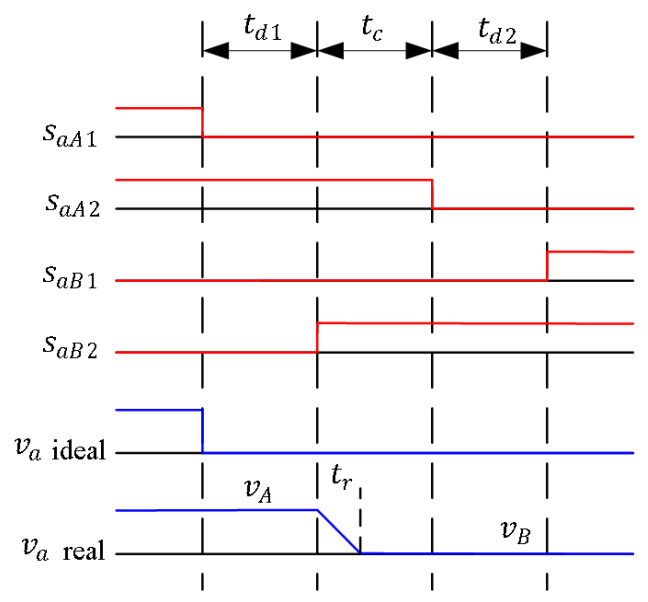

(b)

Fig. 3. Fours-step current based commutation from $A \rightarrow B$ : (a) positive output current, (b) negative output current.

a four-step current based commutation technique is adopted in this work [16]. Considering Fig.1, it is assumed that the commutation happens between input phases $A$ and $B$. Fig.3 shows a four-step current based commutation from input phase $A$ to input phase $B$ for positive and negative output phase current, respectively, assuming that $V_{A}>V_{B} \cdot t_{d 1}$ and $t_{d 2}$ are delay times, $t_{c}$ is commutation time, and $t_{r}$ and $t_{f}$ denote for IGBT rising and falling time, respectively. As can be seen in Fig.3 (a), a hard commutation happens in third step, when switch $S_{a A 1}$ is turned off. While for negative output phase current in Fig.3 (b), a natural commutation happens by turning on the switch $S_{a B 2}$. For the commutation from input phase $B \rightarrow A$, see [16].

As can bee seen from these two figures, there is a voltage error between ideal output phase $v_{a}$ and the actual one, which is expressed as (1) and (2) for positive and negative output current, respectively.

$$
\begin{gathered}
E U_{A \rightarrow B}\left(i_{a}>0\right)=v^{*}-v=-V_{A B}\left(t_{d 1}+t_{c}+t_{f} / 2\right) \\
E U_{A \rightarrow B}\left(i_{a}<0\right)=v^{*}-v=-V_{A B}\left(t_{d 1}+t_{r} / 2\right)
\end{gathered}
$$

The above analysis is extended to one switching cycle as illustrated in Fig.4, considering that both output and input sectors are (1) and output phase current $i_{a}$ is positive. As can be seen from (3) and (4), there is a voltage error which is dependent on the sign of output phase current and amplitude of input phase voltage, which is expressed in (5). From (5) it is concluded that EU effect, adds an extra voltage to the reference value $v^{*}$.

$$
\begin{gathered}
v_{a}(\text { ideal })=\frac{V_{A}\left(T_{P W M}-T_{0}\right)}{T_{P W M}} \\
v_{a}(\text { real })=\frac{V_{A}\left(T_{P W M}-T_{0}\right)}{T_{P W M}}+\frac{3 V_{A}\left(t_{c}+t_{f} / 2-t_{r} / 2\right)}{T_{P W M}} \\
E U=v^{*}-v=-\frac{3 V_{A}\left(t_{c}+t_{f} / 2-t_{r} / 2\right)}{T_{P W M}}
\end{gathered}
$$

The equation (5) can be extended for all input sectors and output phase currents as (6), where $j$ and $i$ denote for input and output phases,respectively [16], [21]. As seen, the EU voltage is dependent on the magnitude of input voltage and the sign of output phase current. The path of input phase voltages for different input sectors are shown in Fig.5. Table I reports the EU voltage error for different input sectors.

$$
\begin{array}{r}
E U_{i}=\frac{-3 V_{j}\left(t_{c}+t_{f} / 2-t_{r} / 2\right)}{T_{P W M}} \cdot \operatorname{sign}\left(i_{i}\right), \\
j=A, B, C, \quad i=a, b, c
\end{array}
$$

TABLE I

EU VOLTAGE ERROR

\begin{tabular}{ll}
\hline \hline Input sectors & $V_{E U}$ \\
\hline 1 & $\frac{-3 V_{A}\left(t_{c}+t_{f} / 2-t_{r} / 2\right)}{T_{P W M}} \cdot \operatorname{sign}\left(i_{i}\right), \quad i=a, b, c$ \\
2 & $\frac{-3 V_{C}\left(t_{c}+t_{f} / 2-t_{r} / 2\right)}{T_{P W M}} \cdot \operatorname{sign}\left(i_{i}\right), \quad i=a, b, c$ \\
3 & $\frac{-3 V_{B}\left(t_{c}+t_{f} / 2-t_{r} / 2\right)}{T_{P W M}} \cdot \operatorname{sign}\left(i_{i}\right), \quad i=a, b, c$ \\
4 & $\frac{-3 V_{A}\left(t_{c}+t_{f} / 2-t_{r} / 2\right)}{T_{P W M}} \cdot \operatorname{sign}\left(i_{i}\right), \quad i=a, b, c$ \\
5 & $\frac{-3 V_{C}\left(t_{c}+t_{f} / 2-t_{r} / 2\right)}{T_{P W M}} \cdot \operatorname{sign}\left(i_{i}\right), \quad i=a, b, c$ \\
6 & $\frac{-3 V_{B}\left(t_{c}+t_{f} / 2-t_{r} / 2\right)}{T_{P W M}} \cdot \operatorname{sign}\left(i_{i}\right), \quad i=a, b, c$ \\
\hline
\end{tabular}

\section{B. Effect of parasitic capacitors on EU voltage}

In above discussion, a constant turning on and off time for IGBTs was considered in commutation approach, neglecting the effect of parasitic capacitors. In a four-step current based commutation, when the commutation happens from high voltage phase to low voltage phase for positive output phase current, or from low voltage to high voltage phase for negative output phase current, a hard commutation takes place. On the contrary, the commutation from high voltage to low 


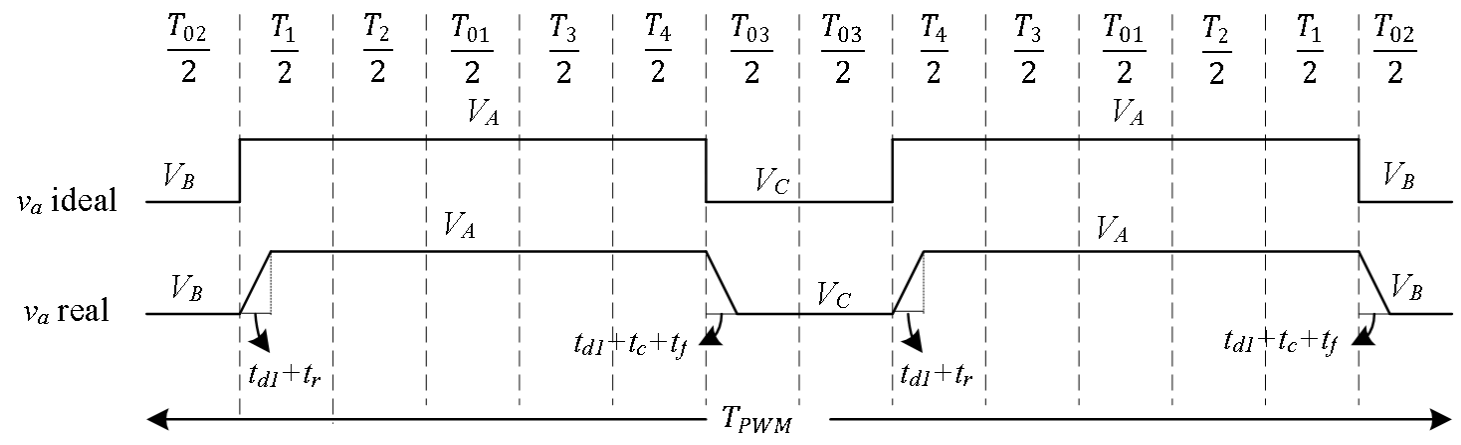

Fig. 4. Fours-step current based commutation.

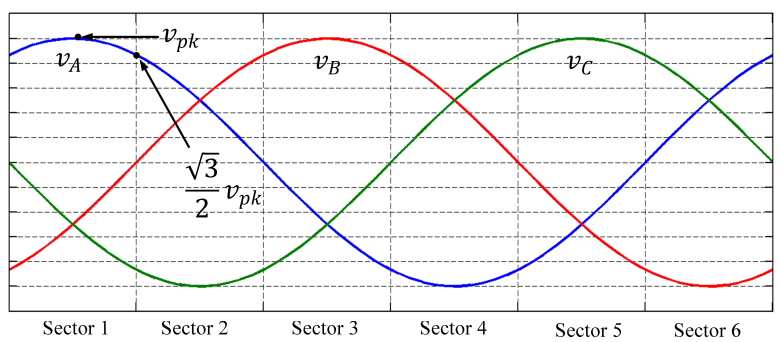

Fig. 5. Input phase voltage path and their sectors.

voltage for negative output current, or from low voltage to high voltage for positive output phase current is a natural commutation [16]. If the effect of parasitic capacitors (see Fig.1) is considered, the hard commutation becomes different compared to previous discussions. As an example, consider the four-step current commutation when $V_{A}>V_{B}$ and $i_{a}>0$, as illustrated in Fig.3 (a). This figure is considered to study the effect of parasitic capacitance, hereinafter. In third step of commutation when switch $S_{a A 1}$ is turned off, the capacitor $C_{p}$ of this switch starts to be charged and the $C_{p}$ of switch $S_{a B 2}$ starts to be discharged. Therefore, the collector-emitter $V_{C E}$ voltage of switch $S_{a A 1}$ increases from ON-state voltage drop to $V_{A B}$, and $V_{C E}$ of switch $S_{a B 2}$ decreases from $V_{A B}$ to ON-state voltage drop. The charging and discharging time $\left(t_{p}\right)$ of these two parasitic capacitors are expressed as (7). From (7) it is concluded that charging and discharging time $t_{p}$ is proportional to size of the capacitor and input phase-to-phase voltage, and also inversely is proportional to the amplitude of output phase current. Therefore, in lower current amplitudes, $t_{p}$ becomes longer. In addition, the term $C_{p}\left(V_{C E}\right)$ denotes that parasitic capacitor is strongly nonlinear and is a function of collector-emitter voltage.

$$
t_{p}=2 C_{P}\left(V_{C E}\right) \frac{V_{A B}}{i_{a}}
$$

To investigate more, the current amplitude for charging and discharging of two capacitors in third step of commutation interval $\left(t_{d 2}\right)$ in Fig.3 (a) is supposed a threshold current $\left(I_{\text {thres }}\right)$ as written in (8). Fig.6 shows three situations for third step of commutation where absolute value of phase current is lower than $I_{\text {thres }}$, equal to $I_{\text {thres }}$, and more than $I_{\text {thres }}$. As can be seen from Fig.6 (c), if the charging and discharging time is longer than $t_{d 2}$, i.e., $\left|i_{a}\right|<\left|i_{\text {thres }}\right|$, the commutation immediately happens when switch $S_{a B 2}$ turns on.

$$
I_{\text {thres }}=2 C_{p}\left(V_{C E}\right) \frac{V_{A B}}{t_{d 2}}
$$

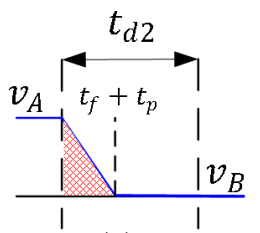

(a)

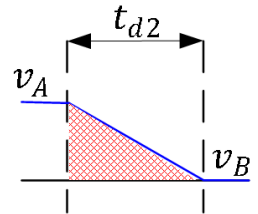

(b)

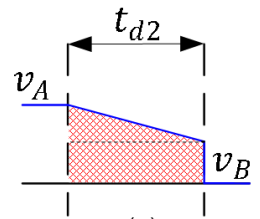

(c)
Fig. 6. Third step commutation of Fig.3 considering parasitic capacitance: (a) $\left|i_{a}\right|>\left|i_{\text {thres }}\right|$, (b) $\left|i_{a}\right|=\left|i_{\text {thres }}\right|$, (c) $\left|i_{a}\right|<\left|i_{\text {thres }}\right|$.

Considering of Fig.6, the volt-time area (VTA) error for third step of commutation are expressed as (9) and (10) for figures (a) and (c), respectively.

$$
\begin{gathered}
V T A_{A \rightarrow B}=V_{B A}\left(t_{f} / 2+t_{p} / 2\right) \text { if }\left|i_{a}\right|>\left|i_{\text {thres }}\right| \\
V T A_{A \rightarrow B}=V_{B A} t_{d 2}+\frac{i_{a} t_{d 2}^{2}}{4 C_{p}} \text { if }\left|i_{a}\right|<\left|i_{\text {thres }}\right|
\end{gathered}
$$

If the above discussion is extended to four-step current based commutation and eventually to one switching cycle (Fig.4), EU voltage error is obtained as (11), where $E U_{i p}$ denotes for EU voltage error for different output phases, considering the parasitic capacitance effect. Also, $E U_{i}$ is the one defined in (6).

$$
E U_{i p}=\left\{\begin{array}{c}
E U_{i}+\frac{-3 V_{j}\left(t_{p} / 2\right)}{T_{P W M}} \cdot \operatorname{sign}\left(i_{i}\right) \\
j=A, B, C, \quad i=a, b, c,\left|i_{i}\right|>\left|i_{\text {thres }}\right| \\
E U_{i}+\frac{-3 V_{j}\left(t_{d 2}-t_{f} / 2\right)}{T_{P W M}} \cdot \operatorname{sign}\left(i_{i}\right)+\frac{i t_{d 2}^{2}}{2 C_{p}} \\
j=A, B, C, \quad i=a, b, c,\left|i_{i}\right|<\left|i_{\text {thres }}\right|
\end{array}\right.
$$

Comparing equations (6) and (11), it is concluded that parasitic capacitance effect adds an extra voltage error to 


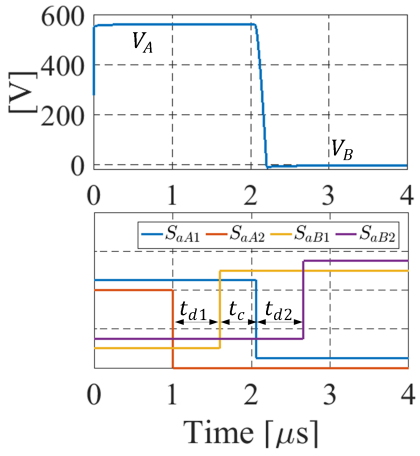

(a)

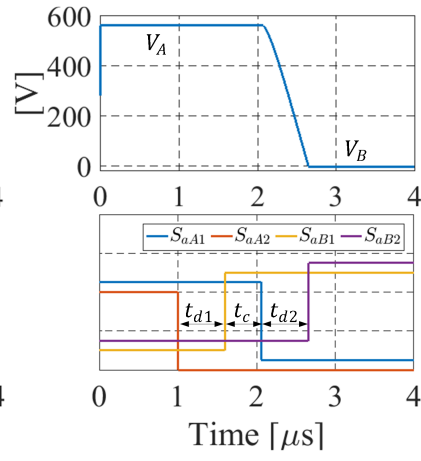

(b)

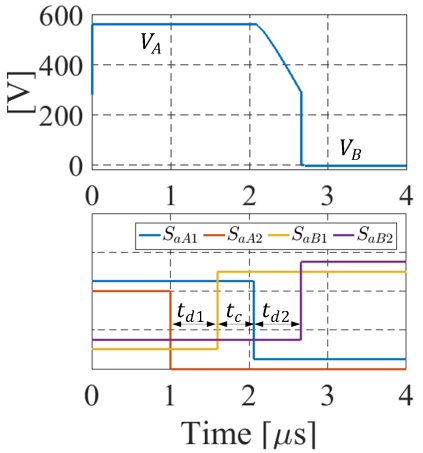

(c)

Fig. 7. Simulation results of current based commutation: (a) $\left|i_{a}\right|>\left|i_{\text {thres }}\right|$, (b) $\left|i_{a}\right|=\left|i_{\text {thres }}\right|$, (c) $\left|i_{a}\right|<\left|i_{\text {thres }}\right|$. Bottom figures denote for gate drive signals.

the EU voltage, while this effect is more evident at lower current values.

In order to validate the analysis of parasitic capacitance effect, a simulation has been done using SPICE model of the component under test for the four-step current based commutation from input phase $A$ to $B$ and positive output current (see Fig.3). The test in Fig.7 (a) was done for $i_{a}>I_{\text {thres }}$, while the tests in Fig.7 (b) and (c) report the results when $i_{a}=I_{\text {thres }}$, and $i_{a}<I_{\text {thres }}$, respectively. As seen, the effect of parasitic capacitance in current based commutation is evident and simulation results verify the analysis.

\section{ON-state voltage drop}

The ON-state voltage drop $\left(V_{D i}\right)$ in matrix converters is approximately modeled as (12), where $V_{t h}$ is forward voltage of power device that is nearly a constant threshold value. The coefficient 2 in this equation means that one diode and one IGBT are conducting at any time. In addition, $R_{d}$ stands for the average resistance of two devices in series. Fig.8 illustrates the current-voltage characteristic of power devise under test. The gray area in the figure reports the operating points in this paper, since the rated current of the motor under test is 7 [A].

$$
V^{*}-V=V_{D i}=2 V_{t h} \operatorname{sign}\left(i_{i}\right)+R_{d} i_{i}, \quad i=a, b, c
$$

\section{Total voltage error}

The total voltage error in MC is obtained by summation of ON-state voltage drop $\left(V_{D i}\right)$ and edge uncertainty voltage
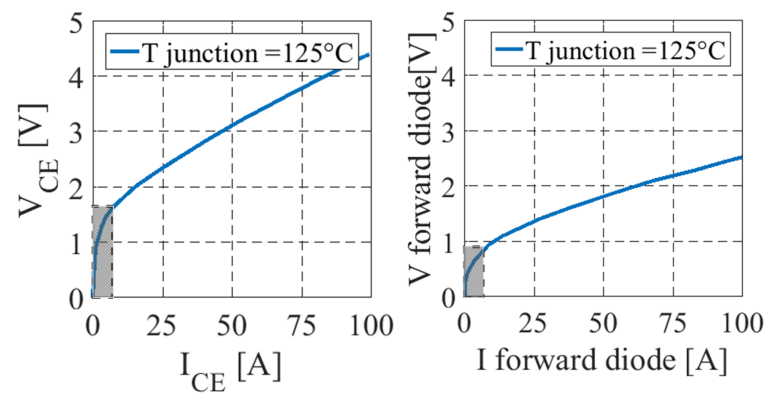

Fig. 8. Current-voltage characteristic of power devise under test. error $\left(E U_{i p}\right)$, as expressed in (13). Considering the equations (6), (11), and (12), it is seen that both ON-state and edge uncertainty errors have one nonlinear part which is dependent on the sign of output phase current, i.e., the coefficients of $\operatorname{sign}\left(i_{i}\right)$. Hence, the total voltage error expressed in (13) can be rewritten as (14), where $V_{t h}^{\prime}$ is the total nonlinear part of $\mathrm{MC}$ voltage error.

$$
\begin{gathered}
v_{e r r, i}=v^{*}-v=V_{D i}+E U_{i p} \\
v_{e r r, i}=V_{t h}^{\prime} \cdot \operatorname{sign}\left(i_{i}\right)+R_{d} \cdot i_{i}
\end{gathered}
$$

It should be commented here that looking at equations (6), (11), and (12), it is seen that for positive current direction, the sign of EU voltage error is negative, while the sign of $\mathrm{ON}$-state voltage drop error is positive, and vice versa for negative current direction. Therefore, the edge uncertainty error and $\mathrm{ON}$-state voltage drop error in four-step current based commutated MC are opposite in sign and tend to cancel out each other.

\section{Proposed Self-Commissioning TeChnique}

The proposed self-commissioning technique is performed using dc-current injection via a simple current control loop which consists of two conventional PI regulators as shown in Fig.9. If a dc-current is injected to the motor $\alpha$-axis at standstill, the motor turns to a resistive load due to zero back-EMF. On the other hand, with dc-current injection, signum function in (14) becomes equal to 1 . Therefore, with considering MC nonlinear voltage errors, the output of PI regulator in $\alpha$-axis $\left(v_{\alpha}^{*}\right)$ for dc current $i_{\alpha}$ is expressed as (15), where $R_{s}$ accounts for motor resistance.

$$
v_{\alpha}^{*}=v_{e r r}+R_{s} i_{\alpha}=V_{t h}^{\prime}+\left(R_{s}+R_{d}\right) i_{\alpha}
$$

The self-commissioning approach consists of two steps which will be explained in the following:

First step: In this step, two dc currents $\left(I_{\alpha 1}^{*}\right.$ and $\left.I_{\alpha 2}^{*}\right)$ are injected to the motor $\alpha$-axis at standstill as illustrated in Fig.9. During each injection interval, $v_{\alpha}^{*}$ and $i_{\alpha}$ are sampled and at the end of each interval they are time averaged. Therefore, equation (15) can be alternatively written as (16) and (17), where $V_{\alpha 1, a v g}^{*}$ and $V_{\alpha 2, a v g}^{*}$ are the average values of 


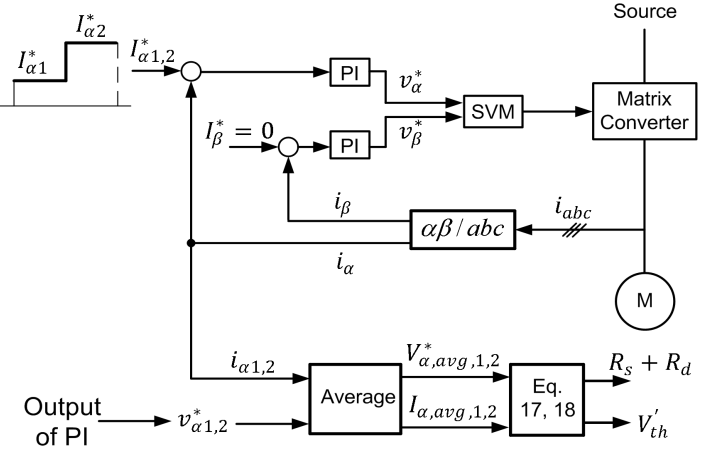

Fig. 9. Closed loop current control scheme to identify MC voltage error and resistive term.

reference voltages and $I_{\alpha 1, \text { avg }}, I_{\alpha 2, \text { avg }}$ are the average values of measured currents at the end of each injection interval.

$$
\begin{aligned}
& V_{\alpha 1, a v g}^{*}=V_{t h}^{\prime}+\left(R_{s}+R_{d}\right) I_{\alpha 1, a v g} \\
& V_{\alpha 2, a v g}^{*}=V_{t h}^{\prime}+\left(R_{s}+R_{d}\right) I_{\alpha 2, a v g}
\end{aligned}
$$

Finally with subtraction (16) from (17), $V_{t h}^{\prime}$ terms cancel out each other and the total resistance is achieved using (18).

$$
R_{s}+R_{d}=\frac{V_{\alpha 2, a v g}^{*}-V_{\alpha 1, a v g}^{*}}{I_{\alpha 2, a v g}-I_{\alpha 1, a v g}}
$$

Second step: after resistance identification in step 1, ascending staircase currents from zero to $13 \mathrm{~A}$ are applied to the $\alpha$-axis, which delta step is $0.2 \mathrm{~A}$, as shown in Fig.10 for the matrix converter under test. The number of steps in this test is 66. In each current step, the current value is put in one of the equations (16) or (17) and ultimately the value of nonlinear voltage error $V_{t h}^{\prime}$ is calculated at the end of each interval and stored in a look-up table. As can be seen from Fig.10, after resistance identification, the nonlinear voltage error $\left(V_{t h}^{\prime}\right)$ identification starts in step 2 and 66 points are stored in LUT as shown with red crosses in lower figure. For the current values higher than $13 \mathrm{~A}, V_{t h}^{\prime}$ is considered a constant value equal to the final value stored in LUT (point 66).

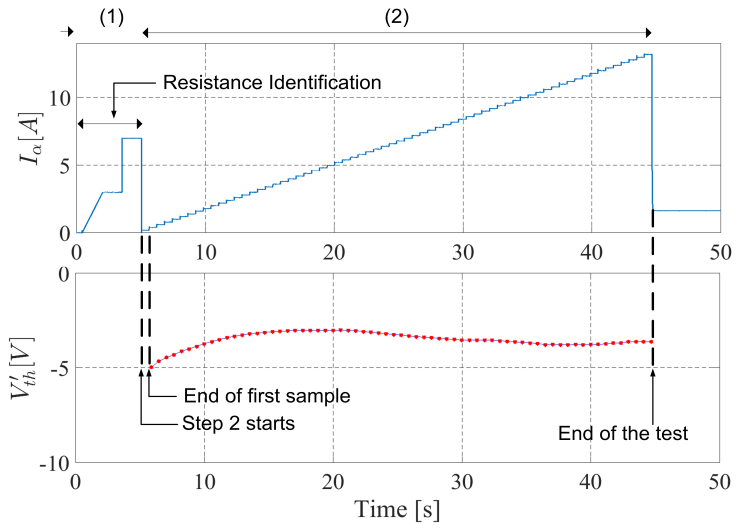

Fig. 10. Self-commissioning technique for identification of MC nonlinear voltage error: (upper):dc current injection in $\alpha$-axis, (lower): $V_{t h}^{\prime}$ identification for different current values.

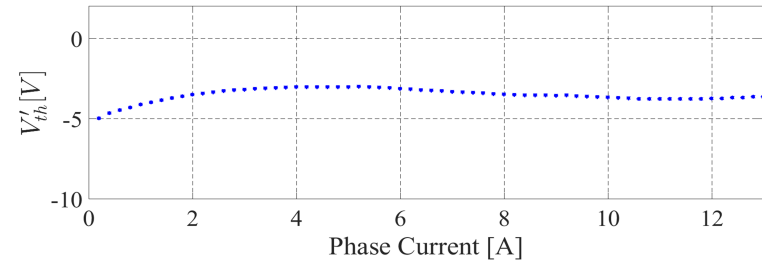

Fig. 11. MC nonlinear voltage error versus different current values.

Finally, Fig.11 reports the MC nonlinear voltage error versus different current values. The negative value of $V_{t h}^{\prime}$ represents that effect of EU voltage error is dominant to the ON-state voltage drop. In addition, it is seen that the absolute value of $V_{t h}^{\prime}$ is higher at lower current values which is expected due to the effect of parasitic capacitance as discussed in section II-B.

\section{A. Nonlinear voltage error compensation}

After identification of MC nonlinear voltage error, this voltage is feed-forward compensated as depicted in Fig.12. As seen, the signum of output three phase currents are calculated and then transformed to stationary $\alpha \beta$ reference frame and multiplied by identified voltage error $V_{t h}^{\prime}$. Finally, the output, $v_{\alpha \beta-\text {-сomp }}$ is feed-forwarded to the reference voltages $v_{\alpha \beta}^{*}$. After this compensation, reference voltages $v_{\alpha \beta}^{*}$ become sinusoidal and used as the input of flux/position observer.

\section{Sensorless Direct Flux Vector Control}

In this section, the sensorless control method for SyR motor drives is briefly explained. The sensorless scheme adopted here is the one presented in [2], which is based on direct flux vector control technique that works at constant switching frequency in stator reference frame called $d_{s} q_{s}$, where the amplitude of stator flux linkage $(\lambda)$ and current on $q_{s}$ axis $\left(i_{q s}\right)$ are the two control variables. The flux amplitude is regulated via $d_{s}$-axis PI regulator, while the $i_{q s}$ is controlled with $q_{s}$-axis channel. The presented sensorless scheme works based on HF signal injection and saliency tracking at standstill and below $100 \mathrm{rpm}$, while it is augmented with $\mathrm{AF}$ based position estimation at higher speeds.

It was shown in [2] that if a HF voltage is injected to the rotor estimated $\hat{d}$-axis, the HF component of the output of flux observer in estimated $\hat{q}$-axis, is expressed as (19), where $\Delta \theta$ denote for rotor position estimation error, $L_{d d}$ and $L_{q q}$ are the $d q$ incremental inductances, and $L_{d q}$ stands for mutual

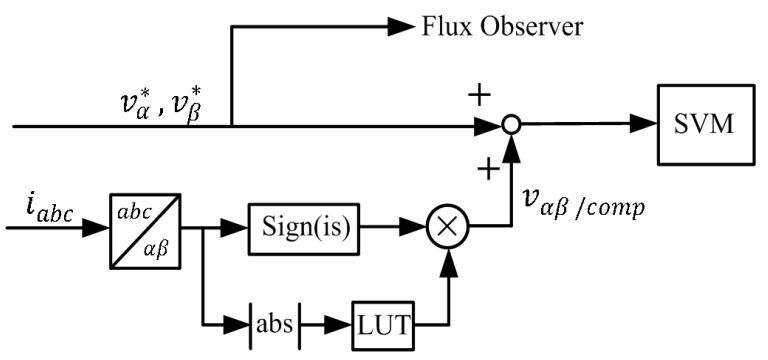

Fig. 12. Compensation of MC nonlinear voltage error. 


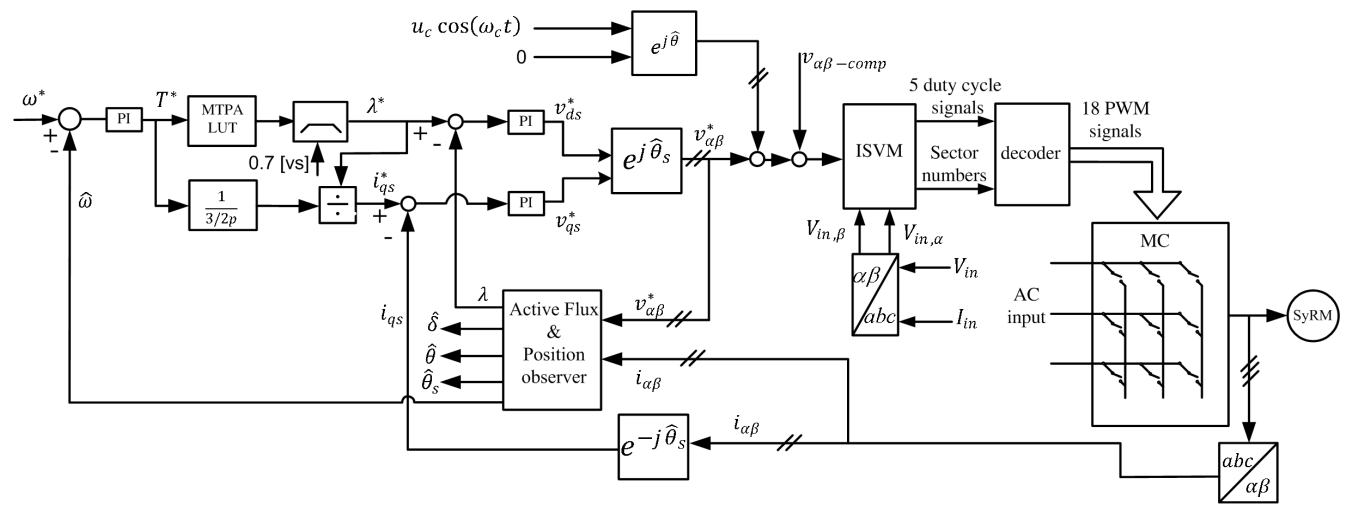

Fig. 13. Sensorless DFVC schematic for matrix converter-fed SyRM drive.

inductance. The term $B$ in (19) is expressed as (20), where $u_{c}$ is the amplitude of injected HF voltage and $\omega_{c}$ is the carrier frequency. In this work $u_{c}$ is $50[\mathrm{~V}]$ and $\omega_{c}$ is $833[\mathrm{~Hz}]$. It is seen from (19) that if $\hat{\lambda}_{\hat{q} H F}$ signal is demodulated and low pass filtered and then sent to a PI regulator to force it to zero, $\Delta \theta$ becomes zero and rotor position is retrieved.

$$
\begin{gathered}
\hat{\lambda}_{\hat{q} H F}=B \cdot\left[L_{q q} \frac{L_{d d}-L_{q q}}{2}-L_{d q}^{2}\right] \cdot \sin (2 \Delta \theta) \\
B=\frac{u_{c} \sin \omega_{c} t}{\omega_{c}\left(L_{d d} L_{q q}-L_{d q}^{2}\right)}
\end{gathered}
$$

On the other hand, at higher speeds above $100 \mathrm{rpm}$, rotor position is estimated based on active flux method. AF components in rotor $d q$ axis are expressed as (21). As seen, the component in $q$-axis is zero and $\mathrm{AF}$ vector lies in rotor $d$-axis. Hence, the position of AF vector which is the output of the flux observer, is identical to the rotor position.

$$
\left\{\begin{array}{l}
\lambda_{d A F}=\lambda_{d}-L_{q} \cdot i_{d}=\left(L_{d}-L_{q}\right) i_{d}=\bar{\lambda}_{A F} \\
\lambda_{q A F}=\lambda_{q}-L_{q} \cdot i_{q}=0
\end{array}\right.
$$

Eventually HF injection and AF methods are are combined together to cover a wide speed range sensorless control. The block diagram of sensorless DFVC of MC-fed SyR motor drive is shown in Fig.13, where the flux control loop bandwidth has been set at $500 \mathrm{~Hz}\left(K_{p}=3150, K_{I}=100000\right)$ and $q_{s}$-axis current control loop has been set at $300 \mathrm{~Hz}\left(K_{p}=75\right.$, $K_{I}=3000$ ). Active flux and position observer block is the key building block in sensorless control, whose details can be found in [2].

\section{EXPERIMENTAL RESUlTS}

In this part experimental results are presented to verify the proposed method. A view of test rig is shown in Figures 14 and 15. Matrix converter is controlled via a floating point microcontroller (TMS320C6713) and a FPGA. In addition, from Fig.15 it is seen that an induction machine is used to impose the load torque or set the speed in the tests. The results are presented in two sections: First, proposed selfcommissioning and compensation technique is investigated.
Then, the results for sensorless control of MC-fed SyR motor drive are presented and the effect of MC nonlinear voltage error on sensorless control is analyzed. The motor and matrix converter under test data are tabulated in Table II.

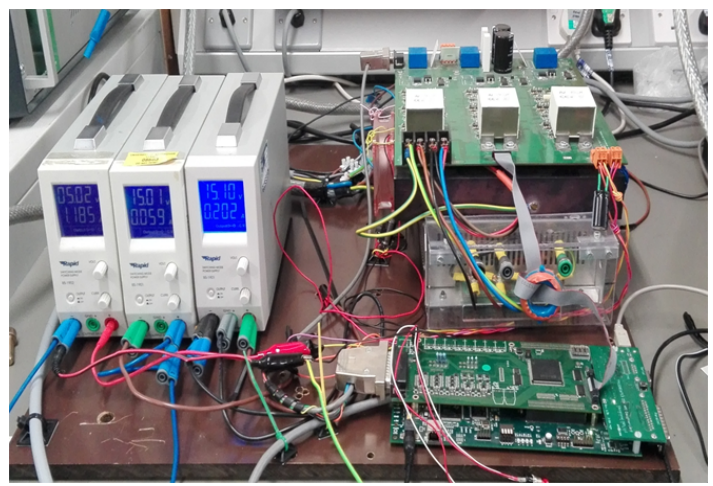

Fig. 14. Matrix converter and its controller board.

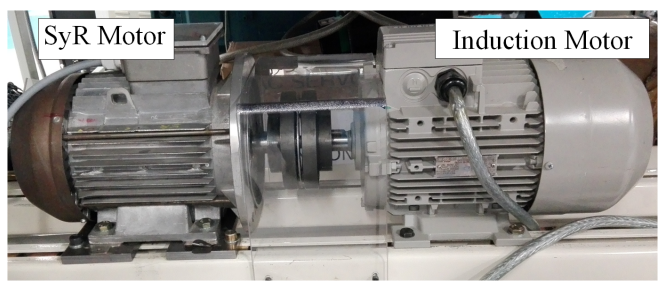

Fig. 15. Synchronous reluctance motor coupled with an induction machine.

\section{A. Self-commissioning and compensation}

As said in section II-A, EU voltage error is dependent on the magnitude of input phase voltage. Therefore, selfcommissioning procedure and $\mathrm{MC}$ nonlinear voltage error identification has been performed for three different input phase voltages of $\mathrm{MC}$ in a range of current from zero to 13 [A] to verify the proposed method. The results are depicted in Fig.16. The voltage error $\left(V_{t h}^{\prime}\right)$ is negative since edge uncertainty voltage error is more than $\mathrm{ON}$-state voltage drop. It is seen from this figure that with the increase of input phase voltage, the absolute value of $V_{t h}^{\prime}$ increases, which is expected. On the other hand, the absolute value of $V_{t h}^{\prime}$ is 
TABLE II

SYR MACHINE AND MC UNDER TEST SPECIFICATIONS

\begin{tabular}{ll}
\hline \hline \multicolumn{2}{c}{ SyR motor under test } \\
\hline Rated power/Number of poles & $2.2[\mathrm{~kW}] / 4$ \\
Nominal Speed/Rated Torque & $1500[\mathrm{rpm}] / 14[\mathrm{Nm}]$ \\
Nominal current & $7[\mathrm{~A}]$ \\
Phase resistance & $3.5[\Omega]$ \\
Moment of inertia $(J)$ & $0.005\left[\mathrm{~kg} \cdot \mathrm{m}^{2}\right]$ \\
\hline \multicolumn{1}{c}{ Matrix Converter: SK $60 \mathrm{GM} 123 \operatorname{module}$} \\
\hline Power device & $1200[\mathrm{~V}], 60[\mathrm{~A}]$ \\
$t_{d 1} / t_{c} / t_{d 2}$ & $0.6[\mu s] / 0.46[\mu s] / 0.6[\mu s]$ \\
Switching frequency $\left(f_{s}\right)$ & $12.5[\mathrm{kHz}]$ \\
Input filter inductance $\left(L_{f}\right)$ & $0.15[\mathrm{mH}]$ \\
Input filter Capacitance $\left(C_{f}\right), \Delta$ con- & $4[\mu F]$ \\
nected & \\
\hline
\end{tabular}

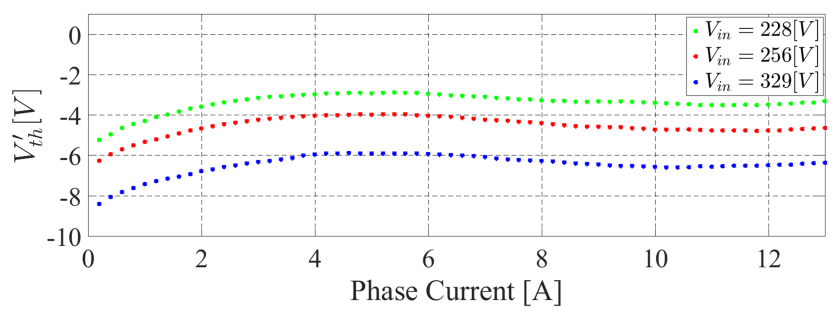

Fig. 16. MC nonlinear voltage error LUT for three different input phase voltages.

higher at low current values for all three different tests which is the effect of parasitic capacitors.

It is noted that hereinafter, all the test are done with the input phase voltage of 329 [V].

To put in evidence the effect of compensation of nonlinear voltages, a simple voltage over hertz $(\mathrm{V} / \mathrm{Hz})$ method has been done at $2.5[\mathrm{~Hz}]$ equal to $75[\mathrm{rpm}]$ for the SyR motor under test. The three-phase output currents are illustrated in Fig.17. Fig.17 (a) represents phase currents when compensation is OFF. As can be seen, the output phase currents are distorted due to MC nonlinear voltage errors. On the contrary, Fig.17 (b) shows the results when compensation of nonlinear voltage errors is ON. It is evident that output phase currents become sinusoidal with compensation technique adopted. In addition, the corresponding voltages in stationary $\alpha \beta$ reference frame for both non-compensated and compensated conditions are illustrated in Fig.18 (a) and Fig.18 (b), respectively. Since this test is $(\mathrm{V} / \mathrm{Hz})$ technique, when the compensation is OFF, the reference voltage is pure sinusoidal. However, when the compensation becomes $\mathrm{ON}$, the nonlinear voltage error is feedforwarded to the reference voltage in order to obtain sinusoidal phase currents.

\section{B. Sensorless control results}

In this section, the results of sensorless DFVC of MC-fed SyR motor are presented. A quadrature encoder with 512 cycle per revolution is used for monitoring purposes.

Fig.19 shows the results for torque control test with $5[\mathrm{Nm}]$ load, where the rotor speed is set at 100 [rpm] via induction

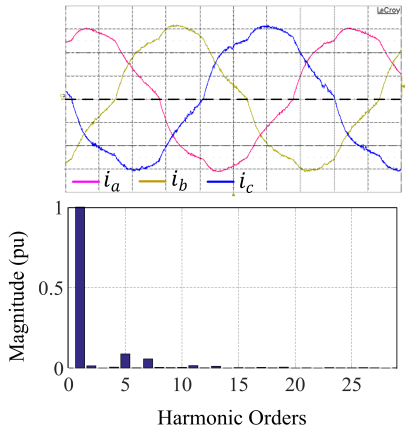

(a)

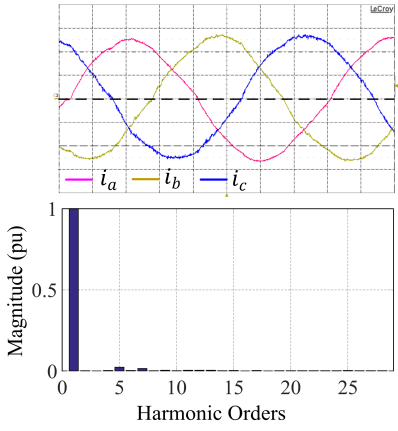

(b)
Fig. 17. Three-phase output currents of MC and their corresponding spectrum, current scale: 1 [A/div], Time scale: 50 [ms/div] (a) compensation of nonlinear error is $\mathrm{OFF}$, (b) compensation is $\mathrm{ON}$.
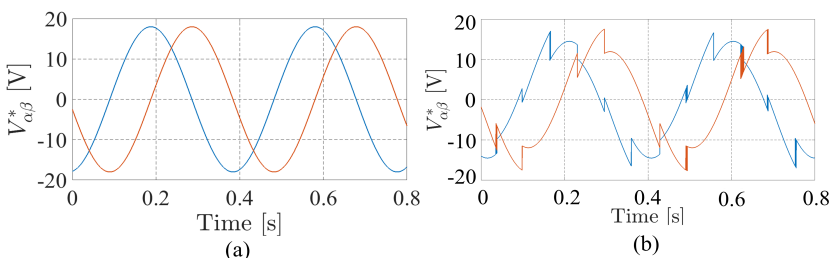

Fig. 18. Stationary reference frame voltages of test of Fig.17. (a) compensation is OFF, (b) compensation is ON.

motor. Three-phase stator currents, observed and actual sin $(\theta)$, and position estimation error $\Delta \theta$ are presented in this test. Fig.19 (a) reports the results when compensation of MC nonlinear voltage error is OFF, and the same test is depicted in Fig.19 (b) for the activated compensation technique. As seen, when the compensation technique is OFF, position estimation error is around $25^{\circ}$ electrical degree which means that MC nonlinearities exert negative impact on position estimation, while the position error is near zero when compensation is $\mathrm{ON}$.
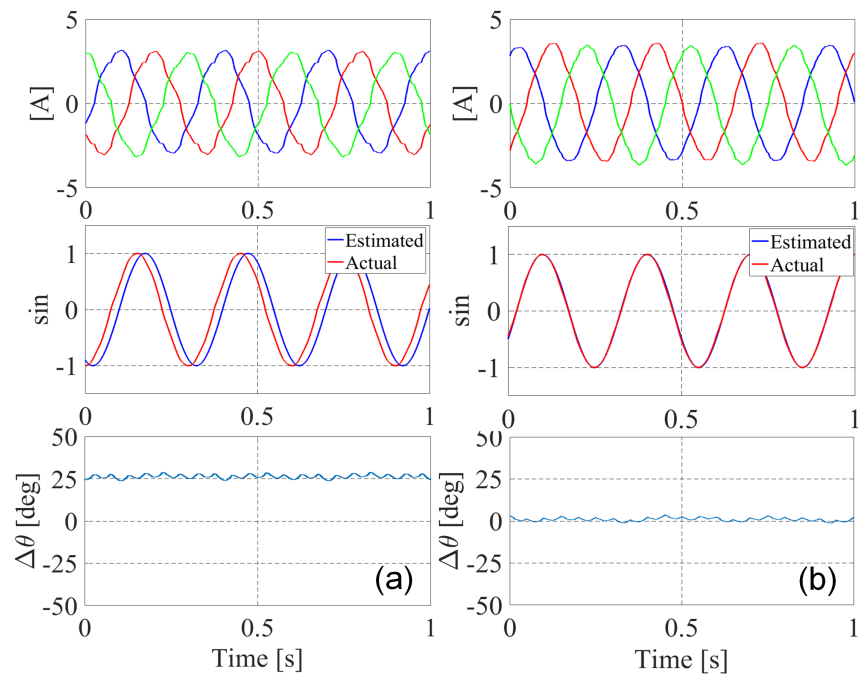

Fig. 19. Torque control test results at $100[\mathrm{rpm}]$ with $5[\mathrm{Nm}]$ load, (a) Compensation of MC nonlinear error is OFF, (b) compensation is ON. From top to bottom: three-phase stator currents; actual and estimated $\sin (\theta)$; position estimation error. 
The performance of sensorless speed control at standstill with step loading is depicted in Fig.20, where 14 [Nm] load (rated torque) is applied to the motor at $t=3[s]$ and at $t=7[s]$ negative step load $(-14[\mathrm{Nm}])$ is imposed to the motor. A torque meter has been used in this test for the sake of comparison between estimated torque and actual torque as seen in the figure. Also, it is seen from this figure that estimated and actual speed are in agreement with each other and position estimation error is near to zero.

Finally, sensorless control performance is examined in speed transient test at no load, where the rotor accelerates to 1000 [rpm] from standstill and again decelerates to -1000 [rpm]. The test results are reported in Fig.21. As seen, the position estimation error is negligible in steady states and under control during speed transients.
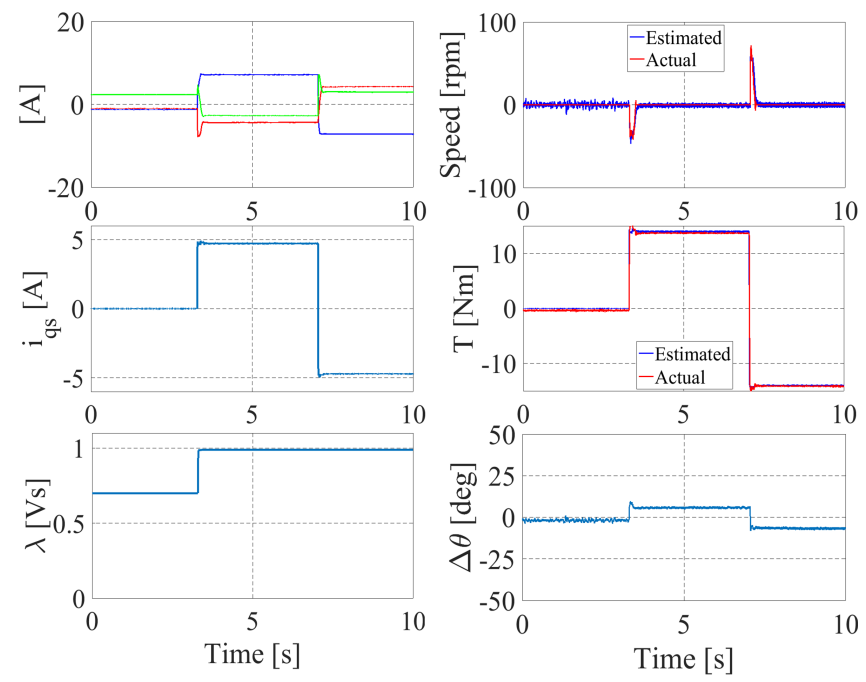

Fig. 20. Sensorless speed control at standstill with nominal step loading.
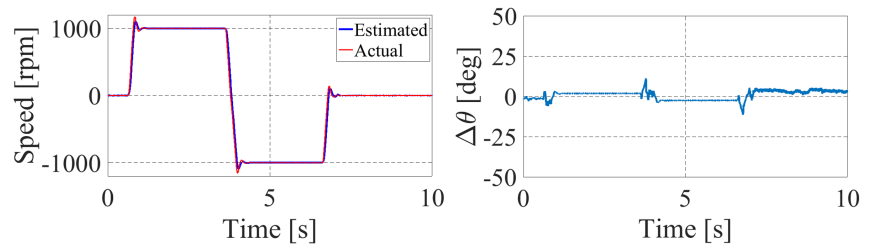

Fig. 21. Sensorless speed transients test at no load condition.

\section{CONCLUSions}

The paper presented a self-commissioning technique for matrix converter nonlinear voltage error identification and compensation. The proposed technique is capable of identifying nonlinear voltage errors before drive startup with no need of IGBT data sheet. An extensive analysis has been addressed for effect of parasitic capacitance on four-step current based commutation. It has been shown that unlike conventional VSIs, parasitic capacitors lead to higher voltage errors at lower current values. Based on this analysis, the self-commissioning method was performed for different current levels and the results have been stored in a look-up table to cover wide range of current values. Finally, proposed technique was applied on a sensorless direct flux vector control method. It has been experimentally proved that without compensation of MC voltage errors, position estimation error is big, while with compensation technique adopted, the position estimation error is around zero.

\section{REFERENCES}

[1] G. Foo, S. Sayeef, and M. F. Rahman. Low-speed and standstill operation of a sensorless direct torque and flux controlled ipm synchronous motor drive. IEEE Transactions on Energy Conversion, 25(1):25-33, March 2010.

[2] A. Yousefi-Talouki, P. Pescetto, G. Pellegrino, and I. Boldea. Combined active flux and high-frequency injection methods for sensorless direct-flux vector control of synchronous reluctance machines. IEEE Transactions on Power Electronics, 33(3):2447-2457, March 2018.

[3] Y. Zhao, W. Qiao, and L. Wu. Improved rotor position and speed estimators for sensorless control of interior permanent-magnet synchronous machines. IEEE Journal of Emerging and Selected Topics in Power Electronics, 2(3):627-639, Sept 2014.

[4] I. Boldea, M. C. Paicu, and G. D. Andreescu. Active flux concept for motion-sensorless unified ac drives. IEEE Transactions on Power Electronics, 23(5):2612-2618, Sept 2008.

[5] Y. Murai, T. Watanabe, and H. Iwasaki. Waveform distortion and correction circuit for pwm inverters with switching lag-times. IEEE Transactions on Industry Applications, IA-23(5):881-886, Sept 1987.

[6] Hengbing Zhao, Q. M. J. Wu, and A. Kawamura. An accurate approach of nonlinearity compensation for vsi inverter output voltage. IEEE Transactions on Power Electronics, 19(4):1029-1035, July 2004.

[7] S. Bolognani, L. Peretti, and M. Zigliotto. Repetitive-control-based selfcommissioning procedure for inverter nonidealities compensation. IEEE Transactions on Industry Applications, 44(5):1587-1596, Sept 2008.

[8] J. M. Guerrero, M. Leetmaa, F. Briz, A. Zamarron, and R. D. Lorenz. Inverter nonlinearity effects in high-frequency signal-injection-based sensorless control methods. IEEE Transactions on Industry Applications, 41(2):618-626, March 2005.

[9] L. M. Gong and Z. Q. Zhu. A novel method for compensating inverter nonlinearity effects in carrier signal injection-based sensorless control from positive-sequence carrier current distortion. IEEE Transactions on Industry Applications, 47(3):1283-1292, May 2011.

[10] Y. Park and S. K. Sul. A novel method utilizing trapezoidal voltage to compensate for inverter nonlinearity. IEEE Transactions on Power Electronics, 27(12):4837-4846, Dec 2012.

[11] G. Pellegrino, P. Guglielmi, E. Armando, and R. I. Bojoi. Selfcommissioning algorithm for inverter nonlinearity compensation in sensorless induction motor drives. IEEE Transactions on Industry Applications, 46(4):1416-1424, July 2010.

[12] G. Pellegrino, R. I. Bojoi, P. Guglielmi, and F. Cupertino. Accurate inverter error compensation and related self-commissioning scheme in sensorless induction motor drives. IEEE Transactions on Industry Applications, 46(5):1970-1978, Sept 2010.

[13] P. W. Wheeler, J. Rodriguez, J. C. Clare, L. Empringham, and A. Weinstein. Matrix converters: a technology review. IEEE Transactions on Industrial Electronics, 49(2):276-288, Apr 2002.

[14] L. Empringham, J. W. Kolar, J. Rodriguez, P. W. Wheeler, and J. C. Clare. Technological issues and industrial application of matrix converters: A review. IEEE Transactions on Industrial Electronics, 60(10):4260-4271, Oct 2013.

[15] S. L. Arevalo, P. Zanchetta, P. W. Wheeler, A. Trentin, and L. Empringham. Control and implementation of a matrix-converter-based ac ground power-supply unit for aircraft servicing. IEEE Transactions on Industrial Electronics, 57(6):2076-2084, June 2010.

[16] A. Arias, L. Empringham, G. M. Asher, P. W. Wheeler, M. Bland, M. Apap, M. Sumner, and J. C. Clare. Elimination of waveform distortions in matrix converters using a new dual compensation method. IEEE Transactions on Industrial Electronics, 54(4):2079-2087, Aug 2007.

[17] K. B. Lee and F. Blaabjerg. Correction to "a nonlinearity compensation method for a matrix converter drive". IEEE Power Electronics Letters, 3(2):81-81, June 2005.

[18] Kyo-Beum Lee and F. Blaabjerg. Reduced-order extended luenberger observer based sensorless vector control driven by matrix converter with nonlinearity compensation. IEEE Transactions on Industrial Electronics, 53(1):66-75, Feb 2005. 
[19] A. Arias, C. A. Silva, G. M. Asher, J. C. Clare, and P. W. Wheeler. Use of a matrix converter to enhance the sensorless control of a surfacemount permanent-magnet ac motor at zero and low frequency. IEEE Transactions on Industrial Electronics, 53(2):440-449, April 2006.

[20] K. B. Lee and F. Blaabjerg. An improved dtc-svm method for sensorless matrix converter drives using an overmodulation strategy and a simple nonlinearity compensation. IEEE Transactions on Industrial Electronics, 54(6):3155-3166, Dec 2007.

[21] A. Yousefi-Talouki, G. Pellegrino, M. Mengoni, and L. Zarri. Selfcommissioning algorithm for matrix converter, nonlinearity compensation. In 2015 IEEE Energy Conversion Congress and Exposition (ECCE), pages 4077-4083, Sept 2015.

[22] A. Yousefi-Talouki, F. Stella, S. Odhano, L. de Lilo, A. Trentin, G. Pellegrino, and P. Zanchetta. Sensorless control of matrix converterfed synchronous reluctance motor drives. In 2017 IEEE International Symposium on Sensorless Control for Electrical Drives (SLED), pages 181-186, Sept 2017.

[23] H. She, H. Lin, X. Wang, L. Yue, X. An, and B. He. Nonlinear compensation method for output performance improvement of matrix converter. IEEE Transactions on Industrial Electronics, 58(9):39883999, Sept 2011.

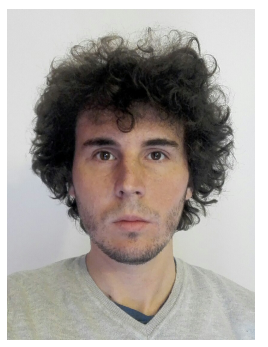

Fausto Stella is a $\mathrm{PhD}$ student of Electrical Engineering at the Politecnico di Torino, Turin, Italy. He received the Bachelors and Masters degrees both in Electrical Engineering from the same university in 2012 and 2015, respectively. In 2017 he was a visiting $\mathrm{PhD}$ student at the University of Nottingham, UK. His research interests include the design of power electronic converters, with focus on $\mathrm{SiC}$ semiconductors and reliability issues, and the control of converters via embedded systems.

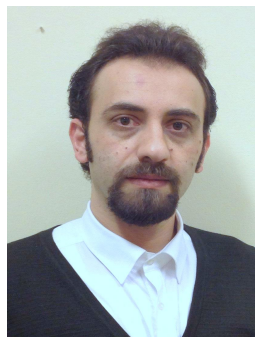

Arzhang Yousefi-Talouki received his B.Sc. and M.Sc. degrees in power electrical engineering from University of Mazandaran, Iran in 2009, and Babol University of Technology, Babol, Iran in 2012, respectively. He received his $\mathrm{PhD}$ degree in electrical engineering from Politecnico di Torino, Turin, Italy in 2017, where he is currently working as a postdoctoral researcher. His current research interests include power electronics, electrical machine drives, especially synchronous motor drives and sensorless control.

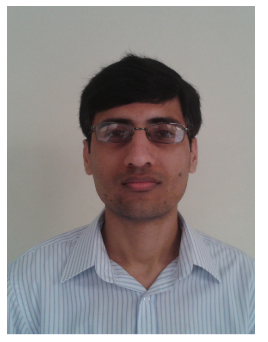

Shafiq A. Odhano (S 13, M 15) received MSc degree in Electrical Engineering from Politecnico di Torino (Italy) from where he obtained his $\mathrm{PhD}$ degree in Power Electronics, Machines and Drives in 2014. He worked with the Politecnico di Torino as a postdoctoral research fellow and is currently with the University of Nottingham (UK) in the same role. Dr Odhanos research interests include high performance control of servodrives, model predictive control of power converters and self-commissioning of ac motor drives. Dr Odhano was the recipient of IEEE-IAS Prize Paper Award for the year 2015.

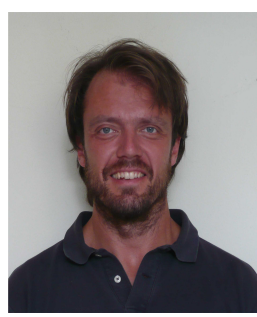

Gianmario Pellegrino (M'06-SM'13) $\mathrm{PhD}$, is an Associate Professor of Electrical Machines and Drives at the Politecnico di Torino, Turin, Italy. Dr. Pellegrino is engaged in several research projects with the industry, and one of the authors of the opensource project SyR-e for the design of electrical motors. He was a visiting fellow at Aalborg university, Denmark, the University of Nottingham, UK, and the University of Wisconsin-Madison, USA. Dr. Pellegrino is an Associate Editor for the IEEE Transactions on Industry Applications and an IEEE Senior Member. He has 36 Journal Papers, One patent, and six Best Paper Awards. $\mathrm{He}$ is one of the proponents and members of the PEIC, the Power Electronics Interdepartmental Laboratory established in 2017 at the Politecnico di Torino, a member of the Advisory Board of PCIM Europe. He is currently the Vice President of the CMAEL Association, representing the field of Power Converters, Electrical Machines and Drives in Italy, and the Advisor to the Rector of Politecnico di Torino for the implementation of interdepartmental centers.

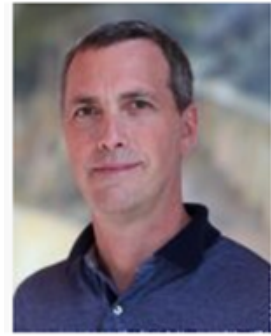

Pericle Zanchetta received his MEng degree in Electronic Engineering and his Ph.D. in Electrical Engineering from the Technical University of Bari (Italy) in 1993 and 1997 respectively. In 1998 he became Assistant Professor of Power Electronics at the same University. In 2001 he became lecturer in control of power electronics systems in the PEMC research group at the University of Nottingham UK, where he is now Professor in Control of Power Electronics systems. He has published over 300 peer reviewed papers, he has been Chair of the IEEE-IAS Industrial Power Converter Committee IPCC and he is now Vice-Chair of the IEEE-IAS Industrial Power Conversion Systems Department (IPCSD). His research interests include control of power converters and drives, Matrix and multilevel converters. 